\title{
BODIPY star-shaped molecules as solid state colour converters for visible light communications
}

D. A. Vithanage, P. P. Manousiadis, M. T. Sajjad, S. Rajbhandari, H. Chun, C. Orofino, D. Cortizo-Lacalle, A. L. Kanibolotsky, G. Faulkner, N. J. Findlay, D. C. O'Brien, P. J. Skabara, I. D. W. Samuel, and G. A. Turnbull

Citation: Appl. Phys. Lett. 109, 013302 (2016); doi: 10.1063/1.4953789

View online: https://doi.org/10.1063/1.4953789

View Table of Contents: http://aip.scitation.org/toc/apl/109/1

Published by the American Institute of Physics

\section{Articles you may be interested in}

A saturated red color converter for visible light communication using a blend of star-shaped organic semiconductors

Applied Physics Letters 110, 013302 (2017); 10.1063/1.4971823

Electroluminescence from completely horizontally oriented dye molecules

Applied Physics Letters 108, 241106 (2016); 10.1063/1.4954163

$10.4 \%$ Efficient triple organic solar cells containing near infrared absorbers

Applied Physics Letters 108, 103302 (2016); 10.1063/1.4943653

Extraction of high charge density of states in electrolyte-gated polymer thin-film transistor with temperaturedependent measurements

Applied Physics Letters 108, 203302 (2016); 10.1063/1.4950965

Organic electroluminescent diodes

Applied Physics Letters 51, 913 (1987); 10.1063/1.98799

Very high-efficiency green organic light-emitting devices based on electrophosphorescence

Applied Physics Letters 75, 4 (1999); 10.1063/1.124258

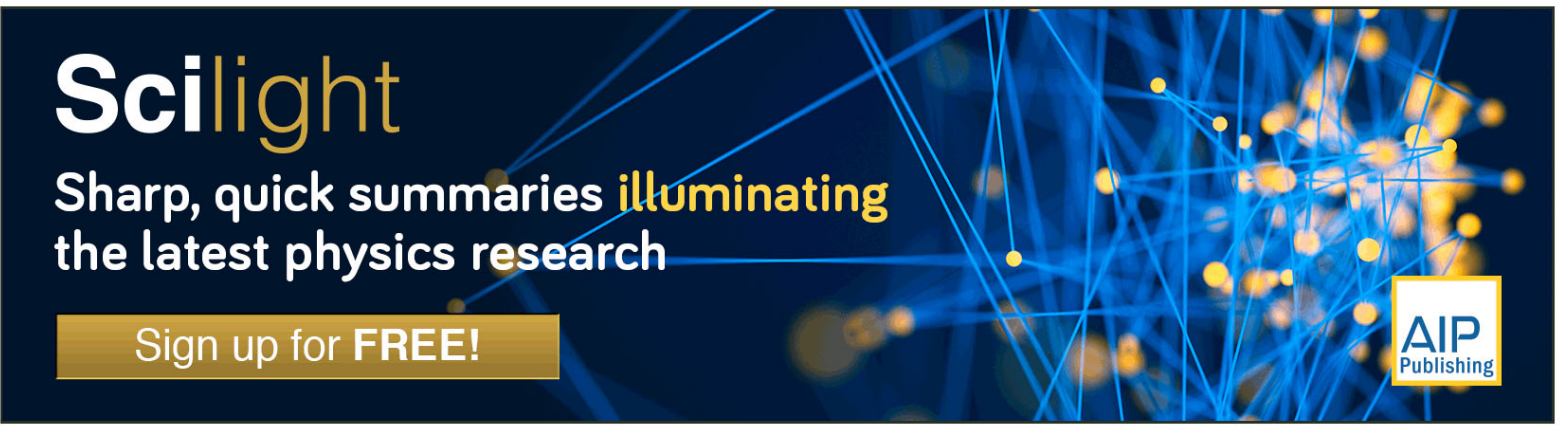




\title{
BODIPY star-shaped molecules as solid state colour converters for visible light communications
}

\author{
D. A. Vithanage, ${ }^{1}$ P. P. Manousiadis, ${ }^{1}$ M. T. Sajjad, ${ }^{1}$ S. Rajbhandari, ${ }^{2,3}$ H. Chun, ${ }^{3}$ \\ C. Orofino, ${ }^{4}$ D. Cortizo-Lacalle, ${ }^{4}$ A. L. Kanibolotsky, ${ }^{4,5}$ G. Faulkner, ${ }^{3}$ N. J. Findlay, ${ }^{4}$ \\ D. C. O'Brien, ${ }^{3}$ P. J. Skabara, ${ }^{4}$ I. D. W. Samuel, ${ }^{1, a)}$ and G. A. Turnbull ${ }^{1, a)}$ \\ ${ }^{1}$ Organic Semiconductor Centre, SUPA, School of Physics and Astronomy, University of St Andrews, \\ St. Andrews KY16 9SS, United Kingdom \\ ${ }^{2}$ School of Computing, Electronics and Mathematics, Coventry University, Coventry, West Midlands CVI 2JH, \\ United Kingdom \\ ${ }^{3}$ Department of Engineering Science, University of Oxford, Oxford OXI 3PJ, United Kingdom \\ ${ }^{4}$ WestCHEM, Department of Pure and Applied Chemistry, University of Strathclyde, Glasgow G1 IXL, \\ United Kingdom \\ ${ }^{5}$ Institute of Physical-Organic Chemistry and Coal Chemistry, 02160 Kyiv, Ukraine
}

(Received 16 March 2016; accepted 31 May 2016; published online 6 July 2016)

\begin{abstract}
In this paper, we study a family of solid-state, organic semiconductors for visible light communications. The star-shaped molecules have a boron-dipyrromethene (BODIPY) core with a range of side arm lengths which control the photophysical properties. The molecules emit red light with photoluminescence quantum yields ranging from $22 \%$ to $56 \%$. Thin films of the most promising BODIPY molecules were used as a red colour converter for visible light communications. The film enabled colour conversion with a modulation bandwidth of $73 \mathrm{MHz}$, which is 16 times higher than that of a typical phosphor used in LED lighting systems. A data rate of $370 \mathrm{Mbit} / \mathrm{s}$ was demonstrated using On-Off keying modulation in a free space link with a distance of $\sim 15 \mathrm{~cm}$. Published by AIP Publishing.

[http://dx.doi.org/10.1063/1.4953789]
\end{abstract}

Organic semiconductors have been widely studied in the last few decades for optoelectronic devices such as transistors, ${ }^{1}$ lasers, ${ }^{2-4}$ amplifiers, ${ }^{5}$ solar cells ${ }^{6,7}$ explosive sensors, ${ }^{8}$ and organic light emitting devices (OLEDs). ${ }^{9}$ They are broadband visible emitters whose emission can be tuned by changing the chemical structure, and can have high photoluminescent quantum yields (PLQY) of up to $90 \%$ in undiluted films. ${ }^{5,9,10}$ This combined with simple and low cost solution processing techniques make them attractive materials for optoelectronic devices.

An emerging application area for organic semiconductors is in the field of visible light communications (VLC). Increasing demand for wireless communications has driven research into improving data transmission concepts. ${ }^{11-21}$ The concept of VLC is to use solid state room lighting to transfer data. This idea can exploit lighting installations to their full potential by providing illumination and data communication simultaneously, in an efficient, safe, and low cost method. White LED lighting commonly uses blue LEDs coated with a yellow-emitting phosphor which acts as a colour converter for some of the blue light. An important consideration is the excited state lifetime of the phosphor/colour converter. High data transmission rates require short excited state lifetimes. Phosphors typically have a microsecond lifetime which severely limits the data transmission rate, so there is a need for colour converters with much shorter lifetimes.

Organic semiconductors are attractive alternatives to using phosphors as colour converters for VLC because they have faster radiative lifetime and high PLQY. They can also be modified to emit at any visible wavelength, allowing tuneable colour converters. The potential of using conjugated

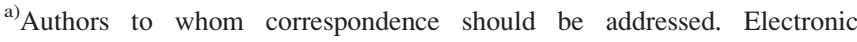
addresses: idws@st-andrews.ac.uk and gat@st-andrews.ac.uk
}

polymers for VLC has recently been demonstrated, using the commercial polymer Super yellow (Merck) in solution. The experiment combined the yellow emission of the polymer with a blue LED to produce white light and a data rate of $1.68 \mathrm{Gbit} / \mathrm{s}$ over a distance of $3 \mathrm{~cm} .{ }^{22}$ Improved colour rendering or wavelength division multiplexing requires fast red colour converters. We have recently shown that borondipyrromethene (BODIPY) molecules in solution can give a saturated red emission, a modulation bandwidth of $39 \mathrm{MHz}$ and data rates of $\sim 98 \mathrm{Mbit} / \mathrm{s}^{23,24}$ However, for practical applications, a compact and solid state structure is required. In this paper, we study a family of star-shaped BODIPY molecules in the solid state and demonstrate that they have an increased bandwidth allowing a data transfer rate of $370 \mathrm{Mb} /$ $\mathrm{s}$ at a distance of $15 \mathrm{~cm}$ with simple on-off keying (OOK).

The molecules (shown in Figure 1, top) have a star shape with boron-dipyrromethene as the core (BODIPY) and oligofluorene arms in a "Y" shaped arrangement. The size of the molecule is modified by increasing the number of fluorene units in each arm from 1 to 4 , and the corresponding molecules are labelled as Y1, Y2, Y3, and Y4. ${ }^{25}$ The oligofluorene arms have a substituent effect on the BODIPY core, and therefore, the increase in the number of arms influences the photophysics of the material.

Solid state colour converters were spin-coated from solution to make thin films on quartz substrates for the photophysical studies. Films of thickness ca. $100 \mathrm{~nm}$ were deposited from solutions at concentrations of 10 and $20 \mathrm{mg} /$ $\mathrm{ml}$ for photophysical and communications measurements, respectively. These were spin-coated at $1500 \mathrm{rpm}$ for $60 \mathrm{~s}$. Figure 1 (bottom) shows the absorption and PL spectra of the films for each molecule. The absorption spectra show peaks at 450 and $620 \mathrm{~nm}$ for $\mathrm{Y} 1 ; 350,473$, and $626 \mathrm{~nm}$ for 
(a)
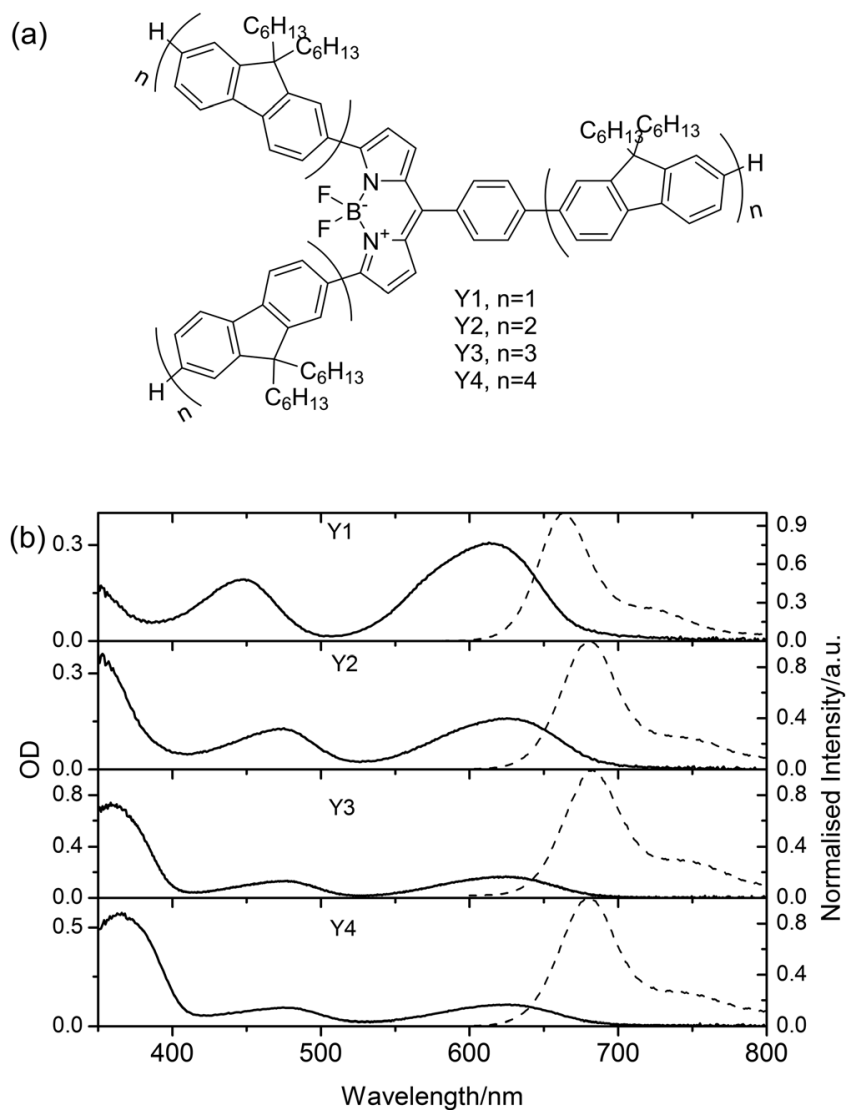

FIG. 1. (a) Molecular structure. (b) Absorption and emission spectra of Y-BODIPY films.

$\mathrm{Y} 2 ; 350,477$, and $625 \mathrm{~nm}$ for $\mathrm{Y} 3$; and 366,480 , and $625 \mathrm{~nm}$ for Y4. The absorption band below $400 \mathrm{~nm}$ is attributed to the fluorene arms and increases in intensity with the arm length. Y1 has a peak in absorption at $450 \mathrm{~nm}$ matching well the emission of the blue LEDs used for lighting, and this feature shifts slightly to longer wavelengths for longer arms as seen in Figure 1. The peak emission wavelengths were in the red region of the spectrum, 663, 679, 682, and $682 \mathrm{~nm}$ for Y1, Y2, Y3, and Y4, respectively. The red PL emission comes from an extended conjugation across the BODIPY core and adjacent fluorene units as has been described previously. ${ }^{24}$ The bathochromic shift from Y1 to Y2 is also evident in solution ${ }^{23,24}$ and indicates that there is a further delocalisation of the excited state across the BODIPY and neighbouring fluorene units.

Time-resolved fluorescence measurements were conducted using the time correlated single photon counting (TCSPC) technique, exciting the materials at $375 \mathrm{~nm}$ and detecting at the corresponding peak PL wavelengths. The $375 \mathrm{~nm}$ excitation is absorbed by the oligofluorene arms, and results in a fast energy transfer to the emitting state that is delocalised across the BODIPY core. The energy transfer is very fast and cannot be resolved by the TCSPC apparatus. The resulting PL dynamics are shown in Figure 2 and have bi-exponential decays. The lifetime values are given in Table I for the nanosecond range and show Y3 having the shortest average decay. The PLQY of the films also differ, showing lower values compared to solutions. In films, the PLQY values range from $22 \%$ to $56 \%$, whereas in solution form they were previously measured to be $55 \%-62 \%{ }^{23}$

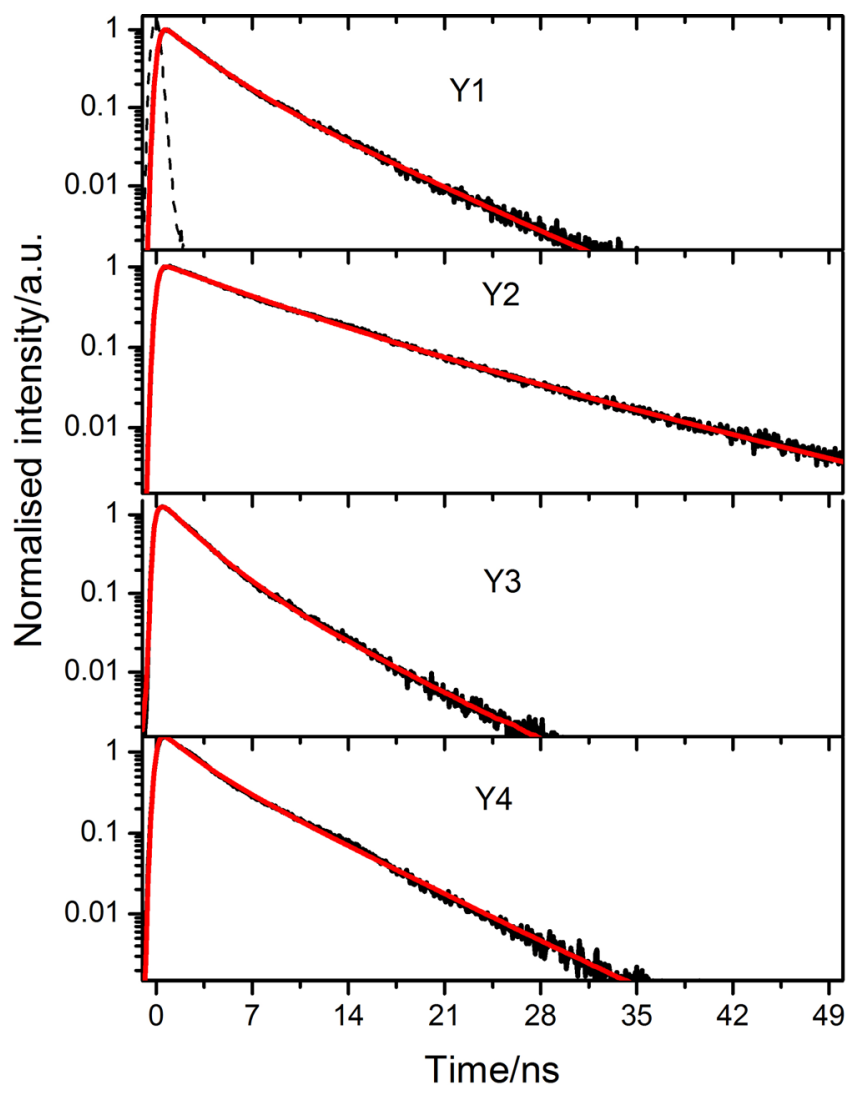

FIG. 2. Time-resolved fluorescence measurements of Y-BODIPY films (black) and their fit (red) with the instrument response function (dashed line).

Films of $\mathrm{Y} 3$ were selected for bandwidth and data transmission measurements as they have the shortest lifetime and high PLQY. Samples were encapsulated under glass using the UV cured epoxy NORLAND 68 on top of the BODIPY Y3 film. UV curing was performed with an $8 \mathrm{~W}$ lamp at $365 \mathrm{~nm}$ for $1.5 \mathrm{~min}$. The encapsulation process was conducted in a nitrogen-filled glove box which had a controlled and inert atmosphere to avoid exposure to water and oxygen molecules, thus reducing photo-oxidation effects during measurements. The photophysical properties of $\mathrm{Y} 3$ were not changed by the encapsulation process.

The capacity of the data link scales with its modulation bandwidth. To assess the bandwidth of Y3, the experimental setup presented in Figure 3(b) was used. The fast (broad bandwidth) excitation source and detector used were a diode laser emitting at $450 \mathrm{~nm}$ and an avalanche photodiode. To eliminate any residual excitation light at the detector, a reflectance geometry was adopted in combination with a suitable longpass dichroic filter. The excitation source was driven by an amplified sinusoidal voltage generated by the network

TABLE I. Photoluminescence quantum yield excited at $375 \mathrm{~nm}$ and lifetime of Y-BODIPY films.

\begin{tabular}{lcccccc}
\hline \hline Polymer & PLQY \% & $\mathrm{A}_{1}$ & $\tau_{1}(\mathrm{~ns})$ & $\mathrm{A}_{2}$ & $\tau_{2}(\mathrm{~ns})$ & $\tau_{\text {avg }}(\mathrm{ns})$ \\
\hline Y1 & 22.4 & 0.44 & 2.35 & 0.56 & 5.3 & 4 \\
Y2 & 55.9 & 0.53 & 5.87 & 0.47 & 10.72 & 8.2 \\
Y3 & 40.6 & 0.48 & 1.9 & 0.52 & 4.3 & 3.2 \\
Y4 & 49.2 & 0.26 & 2.07 & 0.74 & 5.08 & 4.3 \\
\hline \hline
\end{tabular}




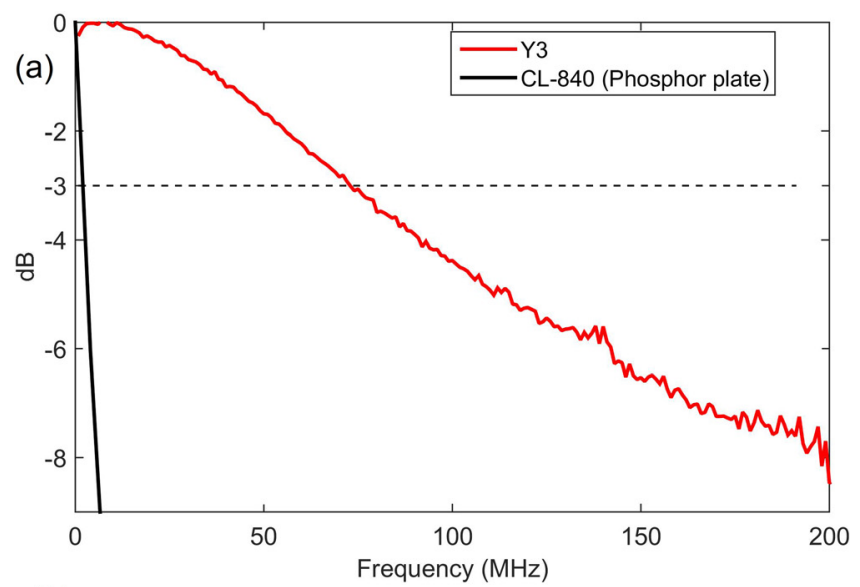

(b)

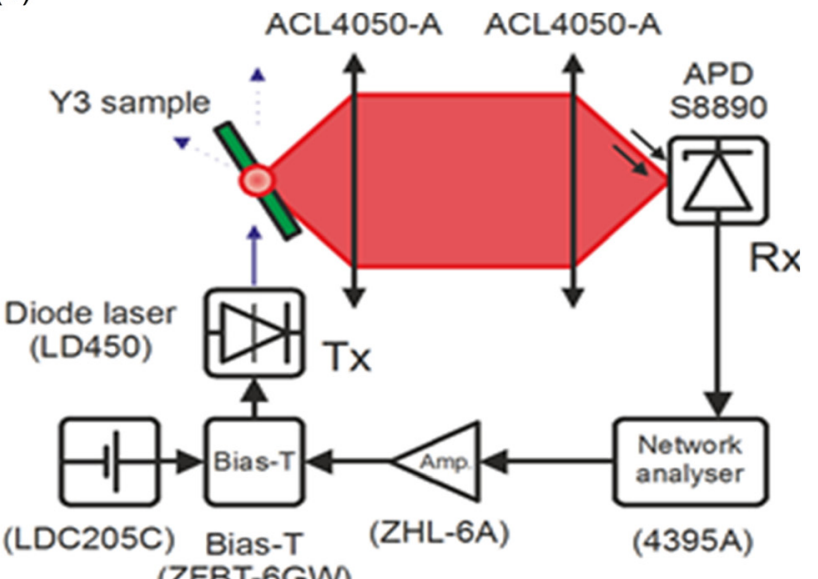

FIG. 3. (a) Result of small signal modulation bandwidth measurement for the Y3 BODIPY. The dotted line corresponds to $-3 \mathrm{~dB}$ attenuation which defines the bandwidth of the system. (b) Experimental setup used for the bandwidth and data transfer measurements.

analyser; this was combined with a DC voltage from a power source using a bias-T. The signal received from the avalanche photodiode (APD) was recorded by the network analyser. To measure the bandwidth of the system, the AC amplitude of the received signal was recorded as a function of the modulation frequency. To factor out the bandwidth contribution of the different components of the experimental setup, first the bandwidth of the measuring system was evaluated by directing the excitation light into the detector. This bandwidth was subsequently subtracted by the network analyser from the recorded bandwidth spectrum for the material. Figure 3(a) shows the results of the bandwidth measurement of the Y3 BODIPY as well as, for comparison, the bandwidth of a commercial phosphor plate CL-840 (Intematix ChromaLit). It is evident in Figure 3 that the BODIPY material has a much higher $-3 \mathrm{~dB}$ bandwidth $(75.5 \mathrm{MHz})$ than that of the phosphor $(5 \mathrm{MHz})$. The Y3 film bandwidth is also twice that measured with the same material in solution.

The data transfer capabilities were also studied using the same setup as for the bandwidth measurements. The excitation laser was modulated in intensity using a binary On-Off Keying $(\mathrm{OOK})^{26}$ modulation scheme, i.e., a binary "one" was represented by a light pulse of duration $1 / \mathrm{Rb}$, where $\mathrm{Rb}$ is the data rate and a "zero" was represented by the absence of the pulse. At the receiver, a simple threshold decoding was used in which the received signal was compared against

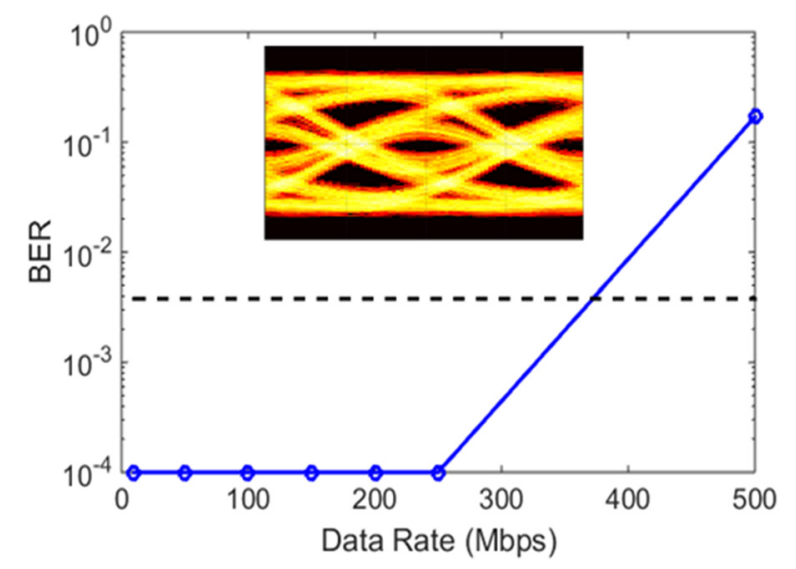

FIG. 4. Plot of BER versus data rate for OOK. The dashed line corresponds to BER of $3.8 \times 10^{-3}$ which is defined as the acceptable error floor for VLC. As inset, the eye diagrams at $250 \mathrm{Mb} / \mathrm{s}$ are presented.

a fixed threshold level based on the expected signal level for "zero" and "one." If the received signal was above the threshold level, it was assumed to be "one," otherwise "zero." Figure 4 shows the measured bit error rate (BER) as a function of transmitted data rate for OOK modulation. The measurements were taken using a pseudorandom binary sequence (PRBS) of $2^{14}-1$, of which $\sim 82000$ bits were analysed at the receiver for errors. Hence, the minimum BER level is limited to $10^{-4}$ to have statistically high confidence level. By considering the forward error correction (FEC) floor of $3.8 \times 10^{-3}$ (as recommended by the International Telecommunication Union (ITU) standard), a data rate of $370 \mathrm{Mb} / \mathrm{s}$ was achieved which is 4 times higher than previously reported for BODIPY colour convertors in solution.

To summarise, BODIPY-cored oligofluorene starshaped conjugated systems have been studied in the solid state to establish their feasibility as a red colour converter for VLC applications. The solid-state films exhibit PL lifetimes shorter than their solution based counterparts and therefore result in a higher bandwidth, for $\mathrm{Y} 3$, of $73 \mathrm{MHz}$ and a data transmission rate of $370 \mathrm{Mb} / \mathrm{s}$, which are, respectively, two and four times higher than measured for Y3 in solution. This bandwidth is 16 times higher than common commercially available phosphors and shows that these organic materials are promising as colour converters for VLC.

We thank EPSRC for financial support from the UPVLC Programme Grant (EP/K00042X/1). I.D.W.S. and P.J.S. are Royal Society Wolfson Research Merit Award holders. The research data supporting this publication can be accessed at http://dx.doi.org/10.17630/20163d03-6cc2-43b6915c-d271f 5220454.

${ }^{1}$ H. Sirringhaus, Adv. Mater. 26, 1319 (2014).

${ }^{2}$ I. D. W. Samuel and G. A. Turnbull, Chem. Rev. 107, 1272 (2007).

${ }^{3}$ S. Chenais and S. Forget, Polym. Int. 61, 390 (2012).

${ }^{4}$ D. Moses, Appl. Phys. Lett. 60, 3215 (1992).

${ }^{5}$ D. Amarasinghe, A. Ruseckas, G. A. Turnbull, and I. D. W. Samuel, Proc. IEEE 97, 1637 (2009).

${ }^{6}$ N. S. Sariciftci, Curr. Opin. Solid State Mater. Sci. 4, 373 (1999).

${ }^{7}$ V. Pranculis, Y. Infahsaeng, Z. Tang, A. Devižis, D. A. Vithanage, C. S. Ponseca, O. Inganäs, A. P. Yartsev, V. Gulbinas, and V. Sundström, J. Am. Chem. Soc. 136, 11331 (2014). 
${ }^{8}$ Y. Wang, P. O. Morawska, A. L. Kanibolotsky, P. J. Skabara, G. A. Turnbull, and I. D. W. Samuel, Laser Photonics Rev. 7, L71-L76 (2013).

${ }^{9}$ J. H. Burroughes, D. D. C. Bradley, A. R. Brown, R. N. Marks, K. Mackay, R. H. Friend, P. L. Burns, and A. B. Holmes, Nature 347, 539 (1990).

${ }^{10}$ J. R. Lakowicz, Principles of Fluorescence Spectroscopy (Springer, 2007).

${ }^{11}$ H. Elgala, R. Mesleh, and H. Haas, IEEE Commun. Mag. 49, 56 (2011).

${ }^{12}$ R. Mesleh, H. Elgala, and H. Haas, paper presented at the IEEE Wireless Communications and Networking Conference (WCNC) (2012).

${ }^{13}$ D. Tsonev, H. Chun, S. Rajbhandari, J. McKendry, S. Videv, E. Gu, M. Haji, S. Watson, A. Kelly, and G. Faulkner, IEEE Photonics Technol. Lett. 26, 637 (2014).

${ }^{14}$ J. Gancarz, H. Elgala, and T. D. C. Little, IEEE Commun. Mag. 51(12), 34 (2013).

${ }^{15}$ D. O’Brien, L. Zeng, H. Le-Minh, G. Faulkner, J. W. Walewski, and S. Randel, paper presented at the Personal, Indoor and Mobile Radio Communications, 2008 (PIMRC 2008) (IEEE, 2008).

${ }^{16}$ Y. Wang, N. Chi, Y. Wang, R. Li, X. Huang, C. Yang, and Z. Zhang, Opt. Express 21(23), 27558 (2013).

${ }^{17}$ R. Kraemer and M. Katz, Short-Range Wireless Communications: Emerging Technologies and Applications (Wiley, 2009).

${ }^{18}$ P. A. Haigh, F. Bausi, Z. Ghassemlooy, I. Papakonstantinou, H. Le Minh, C. Fléchon, and F. Cacialli, Opt. Express 22(3), 2830 (2014).
${ }^{19}$ G. Cossu, A. M. Khalid, P. Choudhury, R. Corsini, and E. Ciaramella, Opt. Express 20(26), B501 (2012).

${ }^{20}$ I. A. Barlow, T. Kreouzis, and D. G. Lidzey, Appl. Phys. Lett. 94, 243301 (2009).

${ }^{21}$ I. A. Barlow, T. Kreouzis, and D. G. Lidzey, Org. Electron. 8, 621 (2007).

${ }^{22}$ H. Chun, P. Manousiadis, S. Rajbhandari, D. A. Vithanage, G. Faulkner, D. Tsonev, J. J. D. McKendry, S. Videv, X. Enyuan, G. Erdan, M. D. Dawson, H. Haas, G. A. Turnbull, I. D. W. Samuel, and D. C. O'Brien, IEEE Photonics Technol. 26, 2035-2038 (2014).

${ }^{23}$ M. T. Sajjad, P. Manousiadis, C. Orofino, D. Cortizo-Lacalle, A. L. Kanibolotsky, S. Rajbhandari, D. Amarasinghe, H. Chun, G. Faulkner, D. O'Brien, P. J. Skabara, G. A. Turnbull, and I. D. W. Samuel, Adv. Opt. Mater. 3, 536 (2015).

${ }^{24}$ C. Orofino-Pena, D. Cortizo-Lacalle, J. Cameron, M. T. Sajjad, P. P. Manousiadis, N. Findlay, A. L. Kanibolotsky, D. Amarasinghe, P. J. Skabara, T. Tuttle, G. A. Turnbull, and I. D. W. Samuel, Beilstein J. Org. Chem. 10, 2704 (2014).

${ }^{25}$ A. L. Kanibolotsky, R. Berridge, P. J. Skabara, I. F. Perepichka, D. D. C. Bradley, and M. Koeberg, J. Am. Chem. Soc. 126(42), 13695 (2004).

${ }^{26} \mathrm{Z}$. Ghassemlooy, W. Popoola, and S. Rajbhandari, Optical Wireless Communications: System and Channel Modelling with Matlab ${ }^{\circledR}$ (CRC Press, 2012). 